\title{
TINJAUAN ANATOMI \\ LAYOUT HALAMAN REPUBLIKA EPAPER
}

\author{
Suprayitno \\ Jurusan Desain Komunikasi Visual, Fakultas Komunikasi dan Multimedia, \\ Universitas Bina Nusantara Jl. KH. Syahdan No.9, Palmerah, Jakarta Barat 11480 \\ praysutoyo@binus.ac.id
}

\begin{abstract}
Communities are increasingly familiar with Internet technology became one of the reasons for the rapid growth of digital newspaper in Indonesia. The ability of the media presents news in brief, fast, accessible and inexpensive form the basis of high growth of consumer interest in digital newspaper / electronic. Technological developments, triggering changes to the newspaper that had shaped the physical print later developed in digital form. In principle, newspaper print and digital newspapers contain messages or the same news, namely providing information to readers about the actual and weighted, as well as other light information that is entertainment. Review the anatomy of the digital newspaper layout is a study to trace and explore what and how the anatomy of a newspaper page layout, at least to provide information and understanding of the anatomy of the layouts in outline. Process layout in the digital version is no different from print media, which distinguishes its output only. In the process to any design layout of a medium, a designer is still expected to possess and master the basic principles such as layout hierarchy, emphasis, balance, and unity.
\end{abstract}

Keywords: Internet technology, digital newspapers, anatomical layout

\begin{abstract}
ABSTRAK
Masyarakat yang semakin akrab dengan teknologi internet menjadi salah satu alasan cepatnya pertumbuhan koran digital di Indonesia. Kemampuan media ini menyajikan berita secara singkat, cepat, mudah diakses, dan murah menjadi dasar tumbuhnya minat yang tinggi konsumen surat kabar digital/elektronik. Perkembangan teknologi, memicu perubahan terhadap koran yang tadinya berbentuk cetak fisik kemudian berkembang dalam bentuk digital. Pada prinsipnya koran cetak maupun koran digital berisi pesan-pesan atau berita yang sama, yakni memberikan informasi kepada pembaca mengenai hal aktual dan berbobot, maupun informasi ringan lainnya yang bersifat hiburan. Tinjauan anatomi layout koran digital ini adalah sebuah kajian untuk menelusuri serta mendalami apa dan bagaimana anatomi layout halaman koran, setidaknya untuk memberi informasi serta pemahaman tentang anatomi layout secara garis besar. Proses layout dalam versi digital tidaklah berbeda dengan media cetak, yang membedakan hanyalah output-nya. Dalam proses me-layout sebuah desain apapun medianya, seorang desainer tetap dituntut untuk memiliki dan menguasai prinsip dasar layout seperti hierarchy/urutan, emphasis/penekanan, balance/keseimbangan, serta unity/kesatuan.
\end{abstract}

Kata kunci: teknologi internet, koran digital, anatomi layout 


\section{PENDAHULUAN}

Internet yang ada sekarang sudah jauh berbeda, awal penemuannya tidak digunakan sebagai media massa seperti sekarang, namun internet ketika itu digunakan untuk kepentingan militer di Amerika Serikat. Departemen Pertahanan Amerika pada tahun 1969 membuat suatu internet untuk menghindari terjadinya informasi terpusat, dengan alasan jika terjadi perang akan mudah dihancurkan. Jadi apabila satu bagian dari sambungan network terganggu dari serangan musuh, maka jalur yang lainnya dapat menggantikan secara otomatis. Setelah digunakan bagi kepentingan militer, kemudian para ilmuwan di Amerika mulai menggunakan internet untuk kepentingan pendidikan seperti penelitian serta pengembangan teknologi. Dan baru setelah itu pemerintah Amerika Serikat memberikan ijin internet untuk kepentingan komersial pada awal tahun 1990. Dan sejak saat itu perkembangan teknologi internet pun mulai melaju pesat dan menyebar ke negara-negara di kawasan Eropa, Asia, Australia, hingga seluruh penjuru dunia.

Internet di Indonesia berkembang berawal dari kreatifitas mahasiswa ITB sebagai paguyuban network yang kemudian berguru kepada Robby Soebiakto yang merupakan guru bagi para amatir radio di Indonesia, khususnya untuk komunikasi data paket radio. Paguyuban network ini menjadi berkembang pesat, hingga pada tahun 1996 merupakan tahun peralihan bagi ITB , karena keterikatan ITB dengan jaringan penelitian Asia Internet Interconnection Initiatives, sehingga memperoleh sambungan data yang lebih cepat.

ISP adalah singkatan dari Internet Serivices Provider yang merupakan jasa layanan sambungan Internet di suatu komputer. ISP yang pertama di Indonesia bernama IndoNET yang dikomersialkan. Setelah itu usaha bisnis Internet di Indonesia mulai marak dengan bermunculannya ISP-ISP baru yang mendapat lisensi dari pemerintah Efisiensi sambungan antar ISP terus dilakukan dengan membangun beberapa Internet Exchange (IX) di Indosat, Telkom, APJII (IIX) dan beberapa ISP lainnya yang saling exchange. Hingga sekarang ini telah banyak ISP di Indonesia yang memberikan kemudahan-kemudahan bagi para pengguna Internet. Seperti TelkomNet Instan yang menggunakan sambungan kabel telpon atau Jogja MediaNet dengan Internet cable-nya, atau kepraktisan CitraNet dengan berlangganan internet secara prabayar. Dengan demikian semakin berkembang teknologi informasi internet di Indonesia dan semakin seru persaingan bisnis internet di Indonesia.

Kemajuan teknologi komputer memberi dampak signifikan dalam dunia jurnalistik. Diawali dengan metode manual dan beralih ke metode berbasis komputerisasi. Pengelolaan, pengiriman dan penyimpanan data, pemanggilan kembali berlipat kali lebih mudah. Melalui media internet ini segala pekerjaan yang biasanya diselesaikan dalam waktu yang cukup lama, kini menjadi sangat singkat. Sehingga dapat menghemat waktu pengerjaannya, karena kecanggihan dari teknologi informasi ini. Proses penyimpanan data, copy paste juga sudah sangat familiar digunakan. Proses pemberitaan dalam format media cetak pun menjadi lebih mudah sehingga memungkinkan produksi secara massif. Perkembangan ini akhirnya membawa kita di era tahun 90-an, di mana teknologi internet mulai dikembangkan. Teknologi nirkabel atau wireless pada notebook/komputer jinjing diciptakan, hingga memudahkan pelaksanaan proses jurnalistik. Koran digital muncul sebagai bentuk perkembangan teknologi komunikasi dan sekaligus menjawab kebutuhan konsumen yang membutuhkan sebaran informasi secara cepat, mudah, dan instan.

Pengembangan media versi cetak yang merambah ke versi digital, membuka peluang dunia baru dalam bisnis online yang disebut dengan media baru. Media baru yang berbasis digital ini meliputi berita online, blog, podcast, streaming video, dan social network atau jejaring sosial. Kehadiran komputer digital ini mengadopsi segala bentuk dari media baru tersebut. Koran digital hadir dalam berbagai bentuk yang antara lain dalam bentuk web, RSS (web feed), dan saat ini yang semakin berkembang adalah bentuk mobile phone dimana koran digital dapat diakses melalui ponsel yang dilengkapi fasilitas 3G dan internet serta konten yang bisa diunduh setiap saat. 
Sejak hadirnya desktop publishing (DTP) serta pengenalan sejumlah aplikasi perangkat lunak grafis, memberi dampak yang signifikan serta mendobrak pola kerja serta kreatifitas para desainer dalam membuat karya desain. Memanipulasi image maupun penciptaan visual 3D adalah pekerjaan yang tidak mudah sebelumnya, kini dengan teknologi komputer memungkinkan desainer untuk melihat hasil layout maupun perubahan tipografi dengan seketika, tanpa menggunakan tinta ataupun pena, bahkan untuk mensimulasikan efek secara digital menjadi begitu mudah.

\section{Definisi}

Asal kata "koran” dari bahasa Belanda: krant, dan dari bahasa Perancis courant. Koran sering disebut juga dengan Harian atau Surat Kabar, adalah suatu penerbitan yang ringan dan mudah direcycle, biasanya dicetak di atas kertas yang relatif murah yakni dengan kertas koran. Surat kabar umumnya berisi berita-berita terkini dalam berbagai topik. Topiknya bisa berupa berita politik, kriminalitas, olahraga, tajuk rencana, cuaca, surat kabar juga biasa berisi komik, TTS dan hiburan lainnya. Seperti yang dikatakan Kasali (1992) "Media cetak adalah suatu media yang statis dan mengutamakan pesan-pesan visual. Media ini terdiri dari lembaran dengan sejumlah kata, gambar, atau foto, dalam tata warna dan halaman putih, serta bersifat memberi informasi dan menghibur”.

Secara harfiah, internet kependekan dari interconnected-networking ialah sistem global dari seluruh jaringan komputer yang saling terhubung menggunakan standar Internet Protocol Suite untuk melayani miliaran pengguna di seluruh dunia. Hanya melalui mesin pencari seperti Google, pengguna di seluruh dunia mempunyai akses Internet yang mudah atas beragam informasi, ketimbang buku atau media yang tercetak, Internet menjadi simbol penyebaran/decentralization, pengetahuan/knowledge, informasi, data dan hiburan/entertainment secara ekstrem.

Kata online sendiri merupakan serangkaian kegiatan aplikasi teknologi, serta proses bisnis yang menghubungkan perusahaan, pembaca, dan komunitas tertentu dalam proses transformasi/ pertukaran, pendistribusian informasi karya tulis secara elektronik.

\section{Sekilas Republika}

Koran Republika merupakan salah satu koran nasional yang lahir dari kalangan komunitas muslim Indonesia. Penerbitan tersebut merupakan upaya kalangan umat Islam, diantaranya wartawan profesional muda yang dipimpin oleh mantan wartawan Majalah Tempo Zaim Uchrowi. Kehadiran Ikatan Cendekiawan Muslim Indonesia (ICMI) yang saat itu diketuai BJ Habibie dapat menembus batasan ketat pemerintah dalam izin penerbitan. Republika terbit perdana pada 4 Januari 1993. Kini Republika semakin profesional dan matang sebagai koran nasional untuk komunitas muslim. Direktur utama Republika saat ini adalah Erick Thohir yang juga sebagai Ketua Umum Asosiasi Televisi Swasta Indonesia (ATVSI) periode 2010 - 2013.

Republika pertama kali terbit tampil dengan menggunakan system grid modular yakni grid block yang tidak lazim, yang kini diikuti oleh banyak koran di Indonesia. Republika juga pernah memperoleh penghargaan juara pertama dalam lomba Perwajahan Media Cetak tahun 1993. Di tahun 1994, Republika juga membuka situs surat kabar pertama serta situs berita pertama di Indonesia. Kemudian pada tahun 1997 menjadi yang pertama mengoperasikan Sistem Cetak Jarak Jauh ( SCJJ ). Pada 31 Januari 2000 Republika menjadi koran pertama yang melakukan resizing. Saat itu umumnya koran di Indonesia menggunakan kertas ukuran sembilan kolom. Hal ini terlalu lebar dan tidak ergonomis. Di dunia pada umumnya koran telah berubah ke ukuran tujuh kolom. Agar pembaca tidak kaget, maka Republika memulai perubahannya dengan ukuran delapan kolom. Ketika seluruh koran pada 2005 berubah ke delapan kolom, maka pada 2 Januari 2006 Republika berubah ke tujuh kolom. Pada 2 Januari 2009 koran terbesar di Indonesia juga kemudian berubah ke tujuh kolom. Republika sejak awal juga menjadi koran pertama sebagai perusahaan terbuka dan telah listing di Bursa Efek Jakarta (BEJ). 


\section{METODE}

Dalam penulisan artikel ini menggunakan analisa formal, pengumpulan bahan-bahan artikelartikel pendukung dari textbooks maupun internet. Kemudian penulis membuat tinjauan analisis mengenai anatomi layout, peran dan fungsi elemen-elemen layout koran Republika ePaper/online.

\section{HASIL DAN PEMBAHASAN}

Membaca koran dalam tampilan cetak di dunia maya secara utuh halaman demi halaman adalah sesuatu hal baru, inilah yang disebut dengan koran ePaper/online digital. Hadirnya era elektronik ternyata membawa dampak yang signifikan bagi perkembangan media, seperti halnya dengan adanya internet, menjadikan kedudukan koran mengalami perubahan, dahulu merupakan barang mewah karena harus dibeli setiap hari, kini dapat dimiliki oleh siapa pun, kapanpun, dan dimana pun selama ia medapatkan akses internet.

Layout koran digital dikerjakan dan dirancang oleh desainer profesioal, sehingga dalam perancangan wajah halaman demi halaman dibutuhkan penanganan yang baik. Tentu saja seorang desainer harus dibekali dengan kemampuan olah desain yang terampil, ditambah dengan pengetahuan yang mumpuni pula. Pemahaman terhadap anatomi layout merupakan hal perlu dimiliki, agar dalam merancang sebuah layout halaman menjadi lebih baik, tidak saja secara estetik namun juga berhasil dalam mengkomunikasikan pesan yang dibawa dalam sebuah media apapun bentuknya, mengutip Yongki (2006:3), "Desain komunikasi visual tidak hanya berfungsi mekanikal tetapi ada fungsi lainnya, yaitu memberi inspirasi, informasi dan menggerakkan kita untuk beraksi”.

Desain komunikasi visual atau lebih dikenal di kalangan civitas akademika di Indonesia dengan kependekan DKV, pada dasarnya merupakan istilah penggambaran suatu proses pengolahan media dalam berkomunikasi mengenai pengungkapan ide atau penyampaian pesan/informasi yang bisa terbaca atau terlihat. Komunikasi visual erat kaitannya dengan penggunaan tanda-tanda (signs), ilustrasi (Ilustration), gambar (drawing), foto (photography), lambang (symbol), huruf (tipografi), warna (color), dan ruang (space), yang kesemuanya berkaitan dengan indera penglihatan.

Proses komunikasi disini melalui eksplorasi ide-ide dengan melibatkan gambar baik itu berupa foto, diagram, warna, penggunaan tipografi yang tepat dan seterusnya, sehingga dapat berdampak positif pada audience. Efek yang dihasilkan tergantung dari tujuan yang ingin disampaikan oleh pengirim pesan (encoder) dan juga kemampuan dari penerima pesan (dekoder) untuk menguraikannya.

\section{Pemahaman Layout}

Mengutip Rustan (2009) “Layout merupakan tataletak elemen-elemen desain terhadap suatu bidang dalam media tertentu untuk mendukung konsep/pesan yang dibawanya.. Definisi layout dalam perkembangannya sudah sangat meluas dan melebur dengan definisi desain itu sendiri, sehingga banyak orang mengatakan me-layout itu sama dengan mendesain”. Kemudian tambahan pula menurut Sukmana (2009:1) "Layout bukan sebatas menata letak material-material/content suatu halaman media. Layout itu tentang bagaimana mengorganisasi-kan ruang”. Jadi pada dasarnya kemahiran desainerlah yang menjadi tolak ukurnya, desainer harus benar-benar paham terhadap materi isi secara keseluruhan sebelum memulai mendesain.

Menurut Bob Gordon \& Meggie Gordon (2006:26) "Ketika kita akan menciptakan layout sebuah halaman berbasis teks, seperti brosur, majalah, dan newsletter, kita memiliki dua elemen bahan 
garapan: yakni konten dalam bentuk gambar dan teks, dan apa yang tersisa yaitu ruang. Seberapa baik kita mengatur keseimbangan antara ruang dan konten adalah kunci untuk keberhasilan dalam melayout". Gordon (2006:16) juga menyarankan agar sebelum mulai membuat desain, harus menentukan struktur yang baik dengan garis bantu yang dinamakan Grid. Grid sebagai alat bantu merupakan elemen yang sangat penting dan menjadi elemen invisible/maya. Bahkan elemen ini menjadi fondasi atau kerangka acuan dalam penempatan semua elemen layout. Termasuk juga membuat margin, yakni menentukan jarak tepi media dengan ruang yang bakal diletakkan elemen-elemen layout.

Dalam bahasan ini me-layout merupakan pekerjaan mendesain juga. Penekanan pada aktifitas ini adalah pemecahan masalah. Layout dalam pengertian yang demikian, menjadi sebuah aktivitas yang tidak sebatas teknis namun juga filosofis, organisatoris, karena sudah melibatkan aspek kognitif, afektif, psikomotorik.

\section{Aplikasi Koran E-Paper/Online}

Semua halaman Republika ePaper ini adalah replika digital, yang konten dan layout halaman seluruhnya sama dengan versi cetaknya. Edisi ePaper pada umumnya harus registrasi terlebih dahulu dengan mengisi aplikasi, seperti halnya pada Koran Republika Online untuk dapat mengaksesnya cukup isi aplikasi/ register.

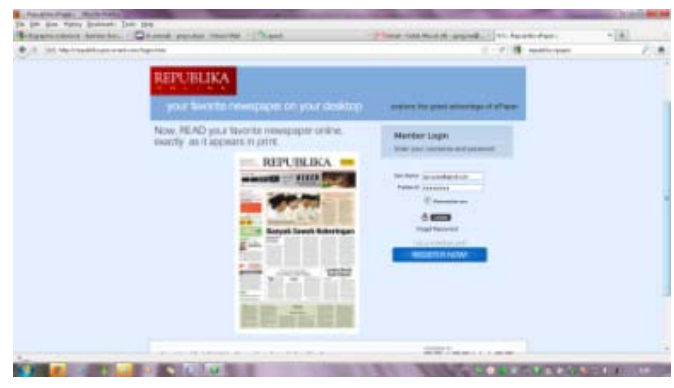

Gambar 1 Halaman aplikasi Republika ePaper/Online

\section{Navigasi Republika E-Paper/Online}

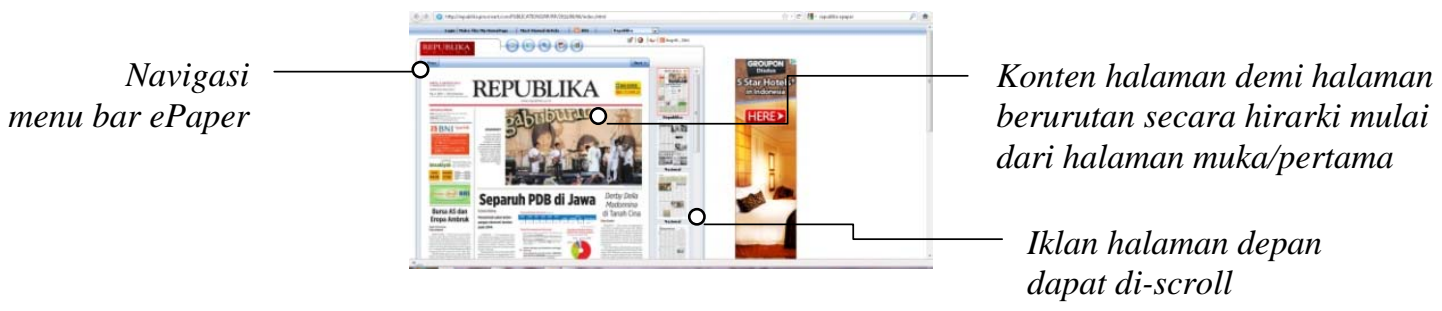

Gambar 2 Navigasi Republika ePaper/Online 


\section{Analisis Anatomi Koran Republika E-Paper/Online}

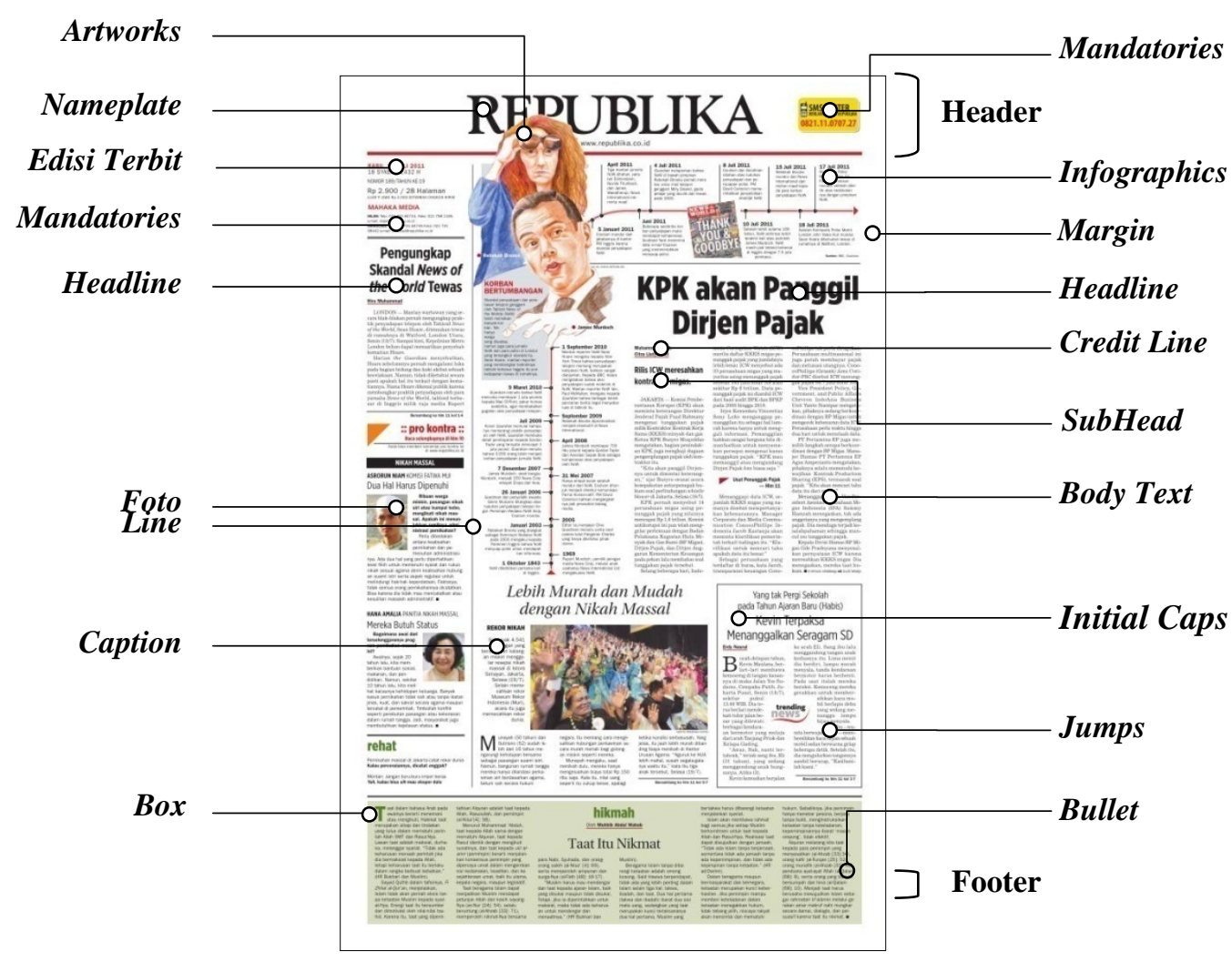

Gambar 3 Halaman depan Republika ePaper/Online

\section{Elemen-Elemen Layout}

Layout sebuah halaman koran terdiri dari banyak elemen yang masing-masing memiliki peran dan fungsi yang berbeda dalam membangun sebuah layout. Sehingga bagi seorang desainer perlu mengetahui serta memahami setiap elemen. Koran cetak maupun digital setidaknya memiliki beberapa elemen diantaranya adalah elemen berbasis teks, dan elemen yang berbasis visual, bahkan ada elemen yang sifatnya invisible/maya, yakni grid dan margin, yang memiliki fungsi sebagai kerangka atau fondasi ‘bangunan' sebuah layout.

\section{Elemen Teks}

Judul, Head, Heading, Headline: Judul adalah satu atau beberapa rangkaian kata singkat, sebagai awal dari sebuah artikel. Judul selain dilihat dari ukuran, juga dapat dilihat dari pemilihan huruf, seperti penggunaan jenis huruf yang bersifat formal ataukah lebih dekoratif sifatnya, disesuaikan dengan isi pesan maupun audience. Peletakan judul harus lebih menonjol agar cepat dilihat pembaca.

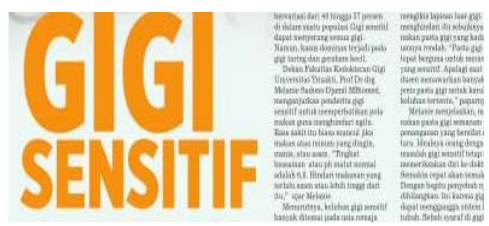

Gambar 4 Contoh Judul Artikel 
Deck, Burlb, Standfish: Deck adalah uraian singkat mengenai topik yang diulas dalam bodytext. Deck memiliki fungsi sebagai pengantar sebelum pembaca memasuki bodytext, dan fungsi ini harus mudah ditangkap oleh pembaca dengan jelas. Seperti pemilihan gaya, jenis huruf yang masih dalam kategoru satu keluarga.

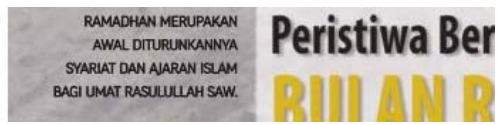

Gambar 5 Contoh Deck

Byline, Creditline, Writer's credit: Byline merupakan nama dari penulis yang dapat disertai dengan jabatan ataupun keteragan singkat lainya. Byline biasanya diletakkan pada akhir naskah, adapula diletakkan sebelum bodytext.

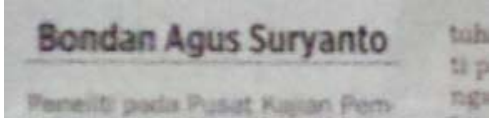

Gambar 6 Contoh Byline

Bodytext, Bodycopy, Copy, Copytext: Bodycopy merupakan elemen layout yang berisikan informasi dari topik yang dibicarakan. Judul yang memikat juga deck yang menarik, dapat menuntun dan memancing pembaca untuk melanjutkan bacaan lebih lengkap melalui bodytext.

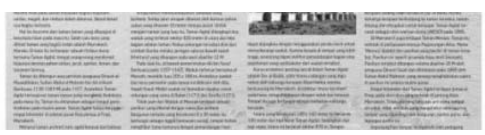

Gambar 7 Contoh Bodytext

Subjudul, Subhead, Crosshead: Subjudul berfungsi sebagai judul dari segmen dalam satu artikel yang panjang. Segmen disini bukan berarti paragraf, melainkan satu pokok atau tema bahasan yang sama. Satu segmen dapat terdiri dari beberapa paragraf.
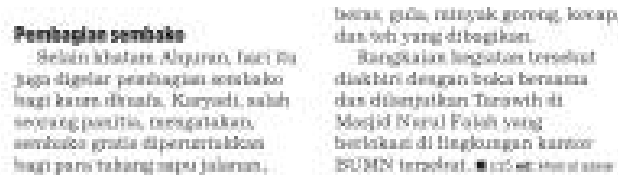

Gambar 8 Contoh Subjudul

Pull Quotes, Liftout: Pada mulanya merupakan cuplikan dari tulisan maupun perkataan seseorang yang di-highlight, namun kini telah mengalami perluasan arti. Pull qoutes lebih sebagai potongan kalimat singkat yang berisi informasi penting yang ingin ditonjolkan, berupa penggalan dari sebagian isi.

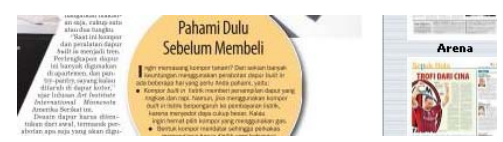

Gambar 9 Contoh Pull Quotes 
Captions, Keterangan gambar: adalah keterangan singkat dari elemen visual maupun inzet, biasanya berukuran lebih kecil dari bodytext dan menggunakan jenis huruf yang berbeda. Caption untuk satu elemen visual biasanya diletakkan berdekatan, namun apabila lebih dari satu elemen peletakkannya dapat bervariasi.

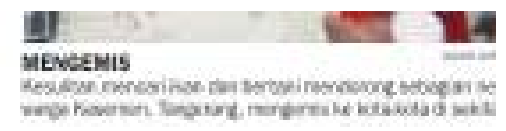

Gambar 10 Contoh Captions

Callouts: pada prinsipnya sama dengan caption, hanya saja callouts biasa dipakai untuk menyertai beberapa elemen visual. Sebagai contoh dalam sebuah diagram callout memiliki garis-garis penghubung dengan bagian elemen visual. Termasuk juga baloon disebut juga callouts.

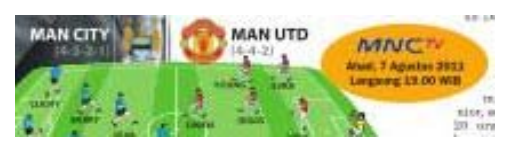

Gambar 11 Contoh Callouts

Initial Caps: adalah huruf pertama yang dibuat berukuran lebih besar, fungsinya lebih bersifat estetis, namun tidak jarang berfungsi juga sebagai penyeimbang komposisi.

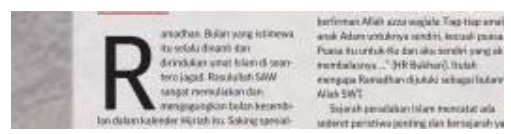

Gambar 12 Contoh Intial Caps

Indent : adalah baris pertama yang menjorok masuk ke-dalam. Sedangkan baris pertama yang menjorok ke-luar disebut Hanging Indent yakni baris pertama tetap, sedangkan baris berikutnya menjorok ke-dalam.

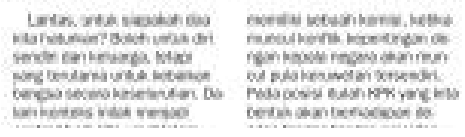

Gambar 13 Contoh Indent

Lead Line: adalah satu kata atau seluruh kata pada baris pertama pada tiap paragraf yang dibedakan atribut hurufnya. Biasanya dibedakan dari jenis huruf/gaya/ukuran/spasi huruf atau leading-nya. Fungsi lead line ini agar mudah dikenali paragraf berikutnya.

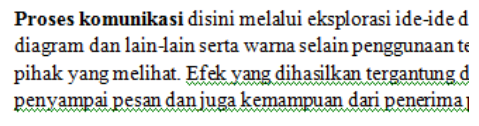

Gambar 14 Contoh Lead Line

Header \& Footer: Area kertas/bidang diantara sisi atas dan margin atas disebut header. Sedangkan footer adalah area kertas/bidang bagian bawah dan margin bawah. Header dan footer biasanya diisi dengan running head, catatan kaki, nomor halaman atau informasi lain. 


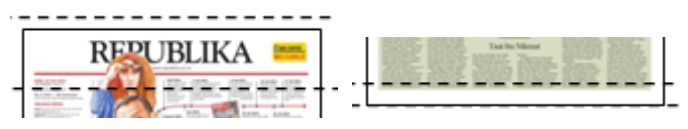

Gambar 15 Contoh Header \& Footer

Running Head, Running Headline, Running Tittle, Running Feet: informasi yang berulang-ulang di setiap halaman seperti Judul, bab/topik, nomor halaman serta info lainnya dengan posisi yang tidak berubah, letaknya di area Header atau footer disebut Running Head.

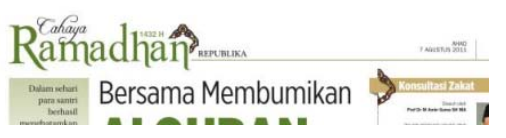

Gambar 16 Contoh Running Head

Nomor Halaman, Page Number: media cetak yang mengunakan lebih dari 8 halaman serta memuat banyak topik, sebaiknya menggunakan nomor halaman guna memudahkan pembaca mencari serta mengingat lokasi artikel. Ada baiknya disertakan daftar isi/index dihalaman depan.

$$
\text { REPUBLIKA RABU, XI JULIIII } 26
$$

Gambar 17 Contoh Nomor Halaman

Jumps, Jumpslines, Continuation Lines: untuk memberi informasi kepada pembaca mengenai naskah yang bersambung. Berisi informasi singkat, "Bersambung ke halaman 12 kol 4-5”, sedangkan di halaman sambungannya tertulis, "Sambungan dari halaman 2". Sambungan ini disebut Continuation Lines.

Bersambung ke hlm. 11 kol. 5-7

Gambar 18 Contoh Jumps

Mandatories, Signatures: Biasanya berisi alamat /nomor telepon, SMS Center, Facimile maupun Logo, agar dapat dihubungi. Untuk berlangganan maupun pemasangan iklan.

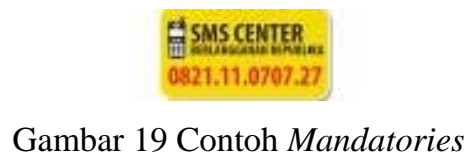

Edisi, Nomor Penerbitan: adalah Nomor Edisi penerbitan, Hari Tanggal Bulan Tahun.

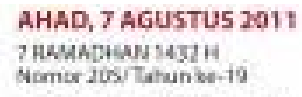

Gambar 20 Contoh Edisi 
Nameplate: adalah nama sebuah media seperti Surat Kabar, Majalah, Tabloid atau Newsletter. Ukuran nama dibuat besar dan diletakkan pada halaman depan bagian atas media tersebut agar terlihat lebih menonjol.

\section{REPUBLIKA}

Gambar 21Contoh Nameplate

Masthead: Merupakan area pada halaman surat kabar/majalah/newsletter yang berisi informasi mengenai penerbitnya: nama-nama pimpinan, para staf, kontributor, cara berlanganan, alamat \& logo penerbit, dan seterusnya. Biasanya masthead diletakkan pada halaman kedua, atau lebih. Umumnya diletakkan berdekatan dengan kata pengantar redaksi.

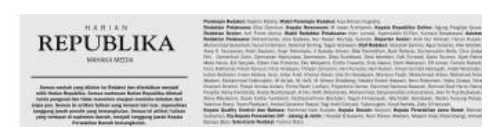

Gambar 22 Contoh Masthead

Judul yang mengundang pembaca, deck yang memberikan ulasan topik bahasan yang padat berisi. Kemudian byline memberi informasi tentang siapa penulisnya, dengan bodytext yang memuat isi bacaan utama, subjudul membagi isi menjadi beberapa segmen, sehingga tidak terlalu panjang dan melelahkan mata, dan seterusnya. Fungsi elemen seperti elemen-elemen teks di atas yang saling berkontribusi dan saling melengkapi hingga menjadikan layout jadi baik dan menarik.

\section{Elemen Visual}

Memahami fungsi masing-masing elemen merupakan modal yang baik sebagai seorang desainer dalam membuat layout. Dan lebih dari itu, seorang desainer diharapkan membekali dirinya dengan pengetahuan yang lebih luas lagi. Selain elemen teks diatas, ada elemen visual yakni semua elemen yang bukan teks, dan kasat mata dalam sebuah layout.

Foto, Image: fotografi memiliki kekuatan yang besar, karenanya koran selalu berusaha menampilkan berita serta informasi yang aktual dan akurat, dengan menggunakan visual fotografi menjadi andalan dalam mendukung suatu berita. Pemakaian foto berwarna lebih menarik.

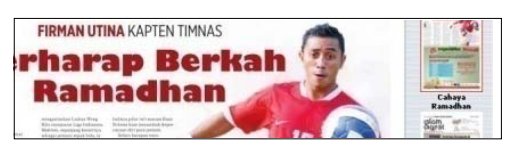

Gambar 23 Contoh Foto

Artworks: Artworks adalah segala jenis karya seni bukan fotografi, baik itu berupa ilustrasi, kartun ataupun sketsa. Karya artworks untuk mendukung sajian berita dalam surat kabar, pemilihan ilustrasi terkadang menjadi lebih efektif ketimbang teknik fotografi.

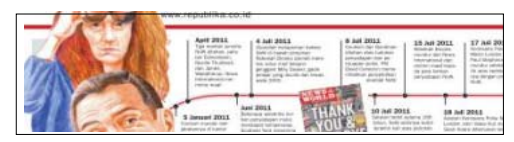

Gambar 24 Contoh Artworks 
Garis, Rules : Garis adalah salah satu elemen desain yang dapat membantu menciptakan kesan estetis, bahkan secara fungsional garis berguna sebagai pembagi area, penyeimbang berat serta sebagai elemen pengikat sistem unity/kesatuan dalam desain.

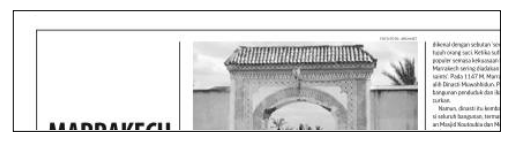

Gambar 25 Contoh Garis

Kotak, Box, Bingkai, Border, Frame: Berisi suplement/artikel tambahan dari artikel utama. Jika diletakkan dipinggir halaman sering disebut "sidebar". Elemen visual terkadang menggunakan kotak agar terlihat lebih rapi.

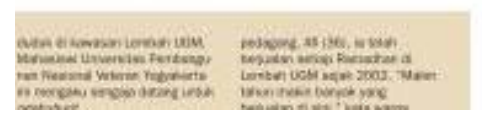

Gambar 26 Contoh Kotak

Point, Bullet: adalah daftar/list yang terdiri dari beberapa baris berurutan ke bawah, umumnya di depan tiap barisnya diberi penanda berupa angka atau point. Dingbat yang merupakan salah satu font symbol, tanda baca atau ornamen, sering dipergunakan sebagai point.

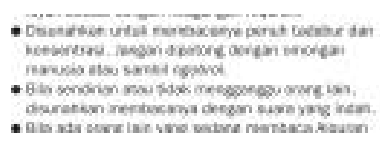

Gambar 27 Contoh Point

Infographic, Informational Graphic: merupakan sajian fakta-fakta berupa data statistik maupun hasil survey penelitian maupun suatu kejadian, yang disajikan dalam bentuk grafik, chart, tabel, diagram, bagan, peta, dan seterusnya.

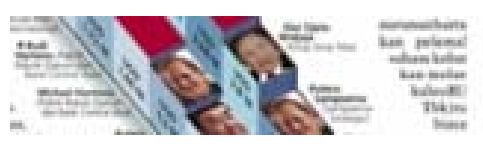

Gambar 28 Contoh Infographic

Inzet, Inset, Inline Graphic: elemen visual yang berukuran lebih kecil, terletak di dalam elemen visual yang lebih besar. Inzet ini berfungsi sebagai informasi pendukung, seperti pada infographic. Seringkali inzet disertakan juga caption atau callouts.

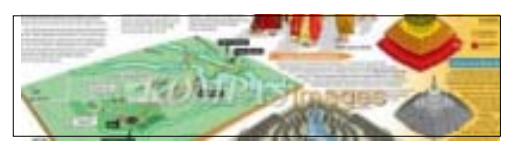

Gambar 29 Contoh Inzet

Elemen Maya : elemen maya ini merupakan fondasi atau kerangka acuan dalam menempatkan seluruh elemen grafis, baik elemen teks maupun elemen visual. Elemen maya inilah yang sebaiknya dirancang terlebih dahulu, kemudian baru memulai menyusun elemen-elemen layout. 
Margin : Jarak antara pinggir area kertas/bidang dengan ruang yang akan ditempati elemen-elemen layout, margin juga berfungsi agar elemen grafis tetap terjaga dan tidak keluar jalur tepi halaman. Terkadang ada juga unsur kesengajaan dalam membuat margin yang dibuat lebih ke pinggir halaman.

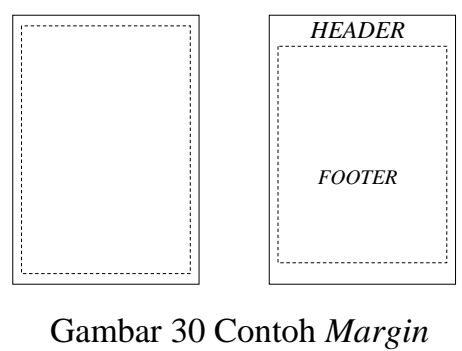

Grid Syste: sistem grid merupakan alat bantu yang sangat penting dalam menyusun sebuah layout. Bahkan dengan grid seorang desainer dimudahkan dalam membagi halaman menjadi beberapa kolom dengan bantuan garis-garis vertikal maupun garis-garis horisontal. Fungsi grid sebagai penjaga konsistensi serta unity dalam menciptakan layout yang lebih terstuktur dan harmoni masih layak digunakan bagi seorang desainer.

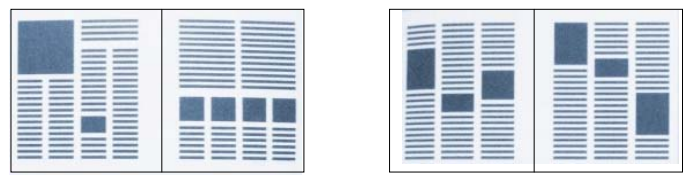

Gambar 31 Contoh Grid

Pada prinsipnya setiap elemen layout yang kasat mata, baik berupa teks maupun visual, merupakan elemen utama dalam membangun sebuah layout, tentunya dengan suatu tujuan dan konsep yang teruji. Desainer haruslah mendasari diri dengan banyak pengetahuan serta pemahanan yang mendalam terhadap prinsip desain serta media olahan, dan berpikir cerdas kepada siapa desain tersebut dibuat, maka setiap desain yang diciptakan akan jauh lebih berdampak positif untuk kemaslahatan masyarakat luas, dan bukan untuk kepentingan diri sesaat.

\section{PENUTUP}

Perkembangan teknologi informasi yang berbasis internet dapat meningkatkan kinerja dan memungkinkan berbagai kegiatan dapat dilaksanakan dengan cepat, tepat dan akurat, hingga akhirnya dapat menumbuhkan kreativitas serta produktivitas desainer. Perkembangan teknologi informasi ini memperlihatkan kemunculannya dalam berbagai jenis kegiatan yang berbasis pada teknologi ini, seperti e-government, e-commerce, e-education, e-medicine, e-laboratory, dan seterusnya yang kesemuanya itu berbasiskan elektronika. Maka hal tersebut menciptakan lahan yang sangat luas untuk dapat di olah seorang desainer grafis. Bagi desainer grafis yang telah lama bergelut dengan media statis dengan pola dan cara lama, ada baiknya mulai melirik dan mencoba membuat layout dengan media yang berbasis digital. Setidaknya ada nuansa berbeda saat mendesain menggunakan media statis dengan media digital. Media digital dengan sendirinya mendapatkan banyak kemudahan di dalamnya. Kelebihan pengguna media statis diantaranya adalah kebiasaan membuat sketsa terlebih dahulu, sebelum memulai me-layout atau mendesain. Bagi desainer yang telah langsung terjun dengan media digital, ada baiknya untuk menuangkan ide-ide kreatifnya dalam bentuk thumnail atau sketsa kasar, karena dengan cara tersebut sangat membantu untuk lebih berfikir secara terstruktur dan terencana. Bukankah me-layout adalah sebuah cara dalam mengorganisir beragam elemen grafis, berupa naskah/artikel, foto, gambar dan ruang. 


\section{DAFTAR PUSTAKA}

Kasali, R. (1992). Manajemen periklanan, konsep dan aplikasinya di Indonesia. Jakarta: Pustaka Utama Grafiti.

Rustan, S. (2009). Layout, dasar \& penerapannya. Jakarta: Gramedia Pustaka Utama. 